\title{
Experimental study of using a PEM fuel cell/battery hybrid system to power small UAVs
}

\author{
B. Omar \\ Faculty of Engineering Science and Technology, \\ Sebha University, Libya
}

\begin{abstract}
Present fuel cell systems have demonstrated a high degree of efficiency for automotive applications and currently the technology is under consideration for use as the potential power source for Unmanned Aerial Vehicles (UAVs). This paper presents an experimental study that was carried out in order to investigate the performance of the Nexa hybrid system (FC/battery) as the main power source for the PiperCub J3 aircraft. A flight scenario was used to investigate the feasibility of using the Nexa FC/battery hybrid system to satisfy the power requirements of the aircraft, including take-off, climb, cruise, descent and landing. In this study, the electric hybrid system consists of a $1.2 \mathrm{~kW}$ proton exchange membrane $\mathrm{FC}$, a unidirectional step-down DC/DC converter and two $12 \mathrm{~V}$ batteries driving an electrical engine. The power delivered to the electrical motor will be from both the FC and battery or from only one of them depending on the power demands. If the battery voltage drops, the FC charges up the batteries at the same time as it delivers power to the motor via converter.
\end{abstract}

\section{Introduction}

Current technological advancements in aviation are pushing towards the more electric aircraft. It is one of the proposed solutions to make aircraft more efficient and subsequently reduce emissions and the environment impact. Fuel cells are among the proposed advances in technology which are under consideration for supplying power to auxiliary power unit (APU) on large commercial aircraft. In 2008, Airbus and its partners used Michelin $20 \mathrm{~kW}$ fuel cell systems onboard in Airbus A320 to power the aircraft's electric motor pump. The motor was 
connected to the blue hydraulic circle and successfully moved the aircraft's ailerons, rudder, and other flight control systems in the flight tests [1, 2].

In the case of smaller aircraft, fuel cells could potentially power the entire aircraft. In 2008, Boeing Company successfully performed flight tests of the first small manned two-seater fuel cell airplane in aviation history. Motor glider of a super Dimona HK36TTC from Diamond Aircraft Industries was replaced by the a proton exchange membrane fuel cell/Li-ion battery hybrid system, which supply power to brushless dc electrical motor that drives a variable pitch propeller. The fuel cell was the primary power source with the battery assisting during takeoff and climb [1, 3]. Romeo and Borello [4] presented a preliminary design of the general aircraft propulsion system for Rapid 200-FC two-seater aircraft. The propulsion system consists of brushless electric motors, inverter, converter, fuel cell and battery. A number of precautions were taken to guarantee the safe operation of each element and the reliability of the system. EnergyOr Technologies Inc. a leading developer of advanced PEMFC systems, demonstrated a long endurance flight of more than 10 hours of a fuel cell powered, operational unmanned aerial vehicle (UAV). In August, 2011, the aircraft FAUCON H2 (complete with integrated avionics) carried out a predetermined flight plan of 10 hours and 4 minutes with an autonomous landing [5].

Despite such demonstrations of fuel cell technology in aircraft applications, there are still many technical challenges to be addressed before fuel cell can become an integrated component on commercial aircraft. Some of those challenges include increasing fuel cell efficiency, reliability and performance in real flight conditions. The reason being, that for aeronautical applications there are many considerations such as variable pressure, temperature ranges and stringent safety requirements which have to be met. For the integration of fuel cell in aircraft design, two important parameters need to be taken into consideration: power to weight ratio $[5,6]$, and fuel cell starting up time. Another factor is hydrogen production and storage, hydrogen does not appear naturally. It has to be extracted from another energy source through a reformation of natural gas or electrolysis. The other challenge is the power management of the fuel cell hybrid system, because a fuel cell alone cannot supply sufficient power in transient response. It has to be in hybrid system with other source such as battery or super-capacitor.

In this experimental study a Nexa Proton Exchange Membrane fuel cell was chosen as the type of fuel cell to act as the main power source, with an assisting battery in order to achieve the desired power at different phases of flight. The advantages of PEM fuel cell is that they operate at relatively low temperatures around $80^{\circ} \mathrm{C}$, which allows them to start up quickly without warming time. Furthermore, PEM fuel cell could deliver high power density up to $1 \mathrm{Acm}^{-2}$ or more and the thinness of the membrane electrode assemblies gives them the advantage of low weight and volume [6, 7]. Hence, it means that compact fuel cell can be manufactured, which make them suitable for the type of application we are interested in. 


\section{Experimental set-up}

The fuel used in the system is Hydrogen. The hydrogen is colourless, odourless and flammable substance. It is highly combustible in the presence of oxygen and burns with a colourless flame. For this reason the Nexa hybrid system had to be installed in well-ventilated lab area equipped with hydrogen alarm sensors, extractor fan and the air quality of the lab is sufficient for fuel cell operation as shown in fig. 1. This section describes component's specification of the fuel cell/battery hybrid system.

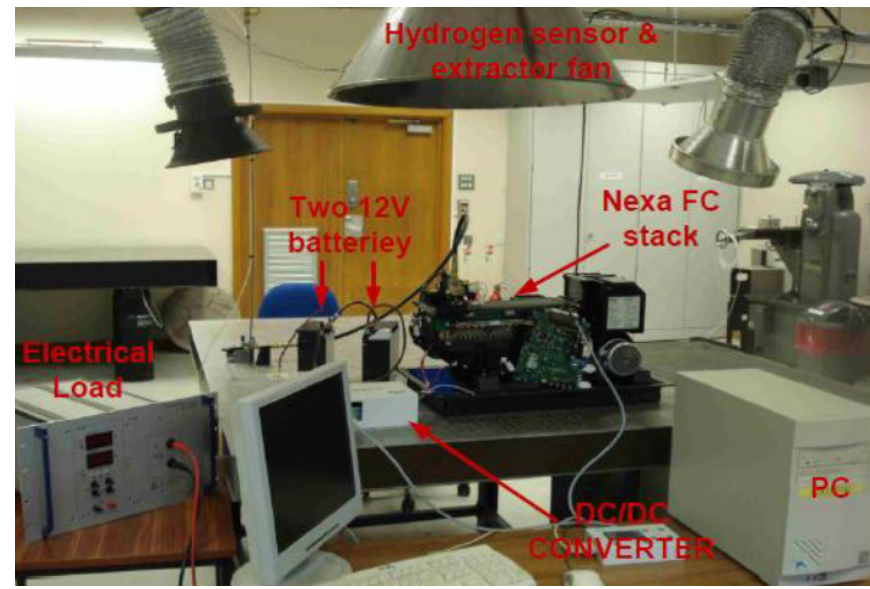

Figure 1: Nexa FC/battery hybrid system.

\subsection{Fuel cell/battery hybrid system}

Experiments were carried out in order to investigate the performance of the Nexa hybrid system (FC/battery) as the main power source for the PiperCub J3 aircraft. The flight scenario to investigate the feasibility of using the Nexa FC/battery hybrid to satisfy the power requirements of the aircraft included take-off, climb, cruise, descent and landing. In this case study, the electric hybrid system consists of a $1.2 \mathrm{~kW}$ proton exchange membrane fuel cell (PEMFC), a unidirectional stepdown DC/DC converter and two $12 \mathrm{~V}$ batteries driving an electrical engine. The fuel cell/battery hybrid architecture enables us to achieve both the high-energy density from the fuel cell and the high-power density from the batteries $[8,9]$ to satisfy the desired power for different phases of flight. A Dualsky XM5050CA DC motor was selected to drive the PiperCub J3. The unidirectional DC converter is connected such that it maintains the output voltage from the FC at $27 \mathrm{~V}$. The rechargeable batteries at the converter output guarantee a stable and dynamic operation of the hybrid system. The power delivered to the electrical motor will be from both the FC and battery or from only one of them depending on the power demands. If the battery voltage drops, the FC charges up the batteries at the same time as it delivers power to the load via converter. 


\subsection{Proton exchange membrane fuel cell}

The $1.2 \mathrm{~kW}$ Nexa fuel cell module employed in this study, the Nexa power module is a small, low maintenance and fully integrated system that produces an unregulated DC power. It contains a Ballard fuel cell stack, and all auxiliary equipment necessary for fuel cell operation. The auxiliary subsystems include hydrogen delivery, oxidant air pump and cooling air supply. Also the Nexa power module has automatic provision to ensure operator safety and prevent equipment damage. A warning or alarm occurs when an unusual or unsafe operating condition occurs, depending on severity. The Nexa power module is quiet, produces zero harmful emissions and permitting indoor operations. The Nexa fuel cell's output voltage level varies from $43 \mathrm{~V}$ at no load to about $26 \mathrm{~V}$ at full load. Net system efficiency is about $50 \%$ at part load and drop to $38 \%$ at full power. The manufacture controlled operating temperature in the stack to be around $65^{\circ} \mathrm{C}$ at the full load. The stack is composed of 47 cells and active area per cell is 115.8 $\mathrm{cm}^{2}$. The system is auto-humidified and air-cooled by a small fan. Regarding the hydrogen feeding of the fuel cell, the fuel is $99.99 \%$ hydrogen (Typically, a 1460 x $230 \mathrm{~mm} \mathrm{~K}$ size industrial gas cylinder weighs $65 \mathrm{~kg}$ and holds 7.2 cubic metres of hydrogen (7200 litres), which has to be compressed at 175 bar) with no humidification, and the hydrogen pressure to the stack is normally maintained at around 1.8 barg. LABVIEW software program is installed to provide a graphical user interface to the Nexa power module's operational status and performance $[10,11]$.

\subsection{Nexa PEMFC polarization characteristics}

According to the manufacture's manual, the Nexa's net output power ranges from zero at system idle to $1.2 \mathrm{~kW}$ maximum and net output current ranges from zero to $46 \mathrm{~A}$ across the operating range of the power plant. An output voltage varies with operating load according to the polarization characteristic of the fuel cell stack, normal idle voltages of the Nexa system are approximately 43V DC at no load to 26V DC at full load. The relationship between the cell voltage and the current density is shown in fig. 2. Characteristic shape of the curve presents three irreversibility regions.

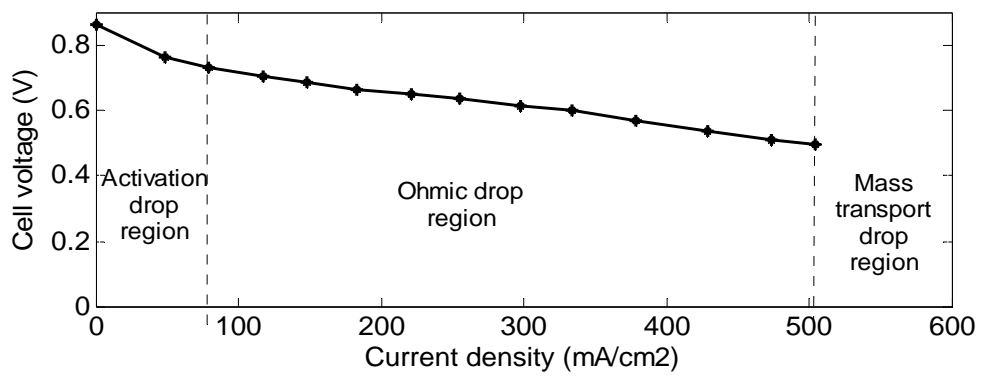

Figure 2: FC polarization characteristic curve. 
First, the activation drop region: in this region the voltage drops rapidly from the normal idle voltage because of the slow starting up the chemical reaction, which takes place in the surface of the electrodes [7]. The voltage losses are driving that chemical reaction to transfer the electrons to or from the electrodes. Secondly, the Ohmic drop region: in this region the voltage drop curve is almost linear as illustrated in fig. 2. It is due to electronic and ionic internal resistances through the electrodes and the electrolyte respectively. The Last region is the mass transport drop region. The voltage should be drops rapidly immediately after Ohmic drop region due to limited of the concentration of the reactants (oxygen and fuel). There is no possibility to record the mass transport region, because, the Nexa power module has an automatic provision to ensure operator safety and prevent equipment damage, driving the system to shut down before the data mass transport region can be recorded.

\subsection{Unidirectional step-down DC/DC converter}

DC/DC converter is required for voltage regulation, and to allow different DC power sources to be connected in parallel. In the fuel cell side, the stack voltage varies from $43 \mathrm{~V}$ to $26 \mathrm{~V}$ depending on the load demand. DC/DC converter BSZ PG 1200 model produced by Isle used as unidirectional converter, it was designed especially to operate with the Nexa fuel cell [12]. It works as a step down converter, regulating the fuel cell voltage and maintaining the bus voltage at bout $27 \mathrm{~V}$.

\subsection{Battery type}

Two $12 \mathrm{~V}$ sealed lead acid batteries were chosen as the secondary power source. In the case that the fuel cell cannot completely meet the power demands in any of the flight phases, the battery will provide the short burst power demands as required. The battery's nominal voltage is $12 \mathrm{~V}$ and rated capacity is 18Ah. Maximum charging current and charging voltage are $5.4 \mathrm{~A}$ and 14 to $15 \mathrm{~V}$, respectively.

\subsection{Electrical load}

In order to simulate a variable power demand and implement the load profile, the energy produced was delivered to an electronic load. ELA1500/75/100D electronic load for DC voltage is from Zentro-Elektrik used in this study. The load has three selectable modes of operation, which are constant current mode, constant resistance mode and constant power mode. IEEE488.2/RS232/USB interface Integrated (with Lab-View driver) for external programming. The current, power or resistance of the load are programmed via an external control voltage. A change in control voltage from 0 to $10 \mathrm{~V}$ changes the set value from 0 to $100 \%$. 


\subsection{Data acquisition and sensors}

The PCI-6259 high speed multifunction M-Series data acquisition (DAQ) board manufactured by National Instruments. It was used to communicate between Matlab (PCI-6259 is supported in Simulink by using the Data Acquisition Toolbox) and the hardware to send and receive data. The external connection, NI SCB-68 shielded I/O connector block used for interfacing I/O signals to plug in data acquisition device with 68-pin connector. The SCB-68 rack gives rugged, very low noise signal termination and compatible with single and dual-connector NI X Series [13]. Single core wire used to connect between sensors and the rack. The sampling time rate was $3.3 \mathrm{~Hz}$. Since the SCB-68 rack can only accept voltage levels up to $10 \mathrm{~V}$, a voltage divider had to be used to step down the voltages that are above $10 \mathrm{~V}$ such as the fuel cell's voltage, the bus voltage and the battery's voltages. The readings were then scaled back in software. The current is sensed by using numerous AMP25 Linear-to-60A hall sensors from Amploc. Amploc current sensors provide galvanic isolation and are capable to measure dc, ac and complex waveforms. Their operation temperatures range from $-55^{\circ} \mathrm{C}$ to $+125^{\circ} \mathrm{C}$. They are light weight, water resistant, window 0.29 inches and the terminals are gold plate (supply voltage, ground and output signal) [14], as shown in fig. 3.
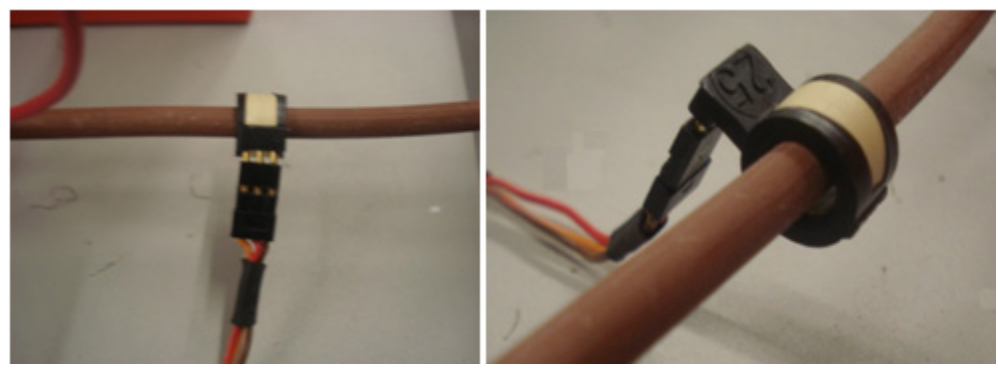

Figure 3: AMP25 Linear-to-60A current sensor.

\subsection{Dynamic response of the engine and load}

This experimental test was to examine the dynamic response of the electrical engine, and compare it with the dynamics of the electronic load. During the test the Nexa FC hybrid system supplied power to the Dualsky XM5050CA DC electric engine under irregular throttle command inputs; and the current demand was recorded. Next the engine current demand load profile was implemented in the programmable Zentro-Elektrik type ELA1500/75/100D electronic load. Fig. 4 shows the load current following the same pattern as the engine current. For instance, at 218 seconds the throttle jumps from low throttle to about 55\% throttle resulting in the engine current to increase from 6.34A to 30A in two seconds, at the same time if we examine the load current, it performs in a very similar fashion, with load current drawing about 30.8A. 


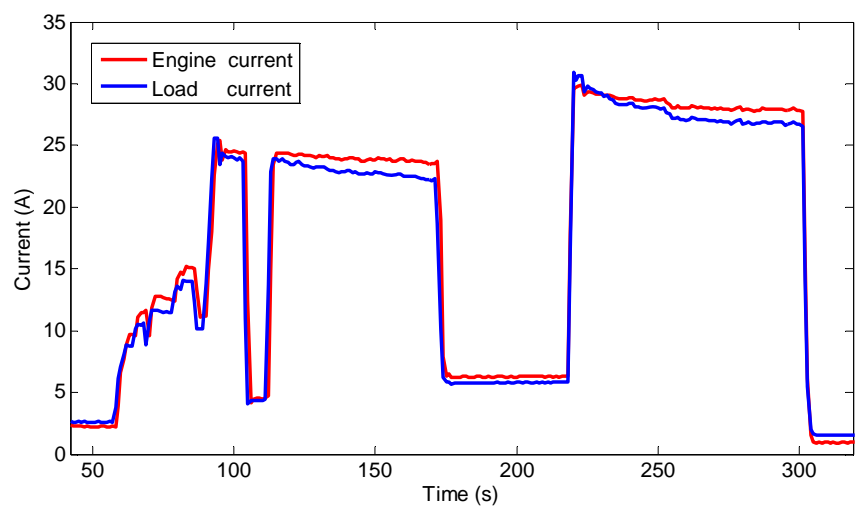

Figure 4: Load and engine current under irregular throttle demand.

\section{Case study}

A flight scenario covering taxi, take-off, climb, cruise, descent and landing was performed in the simulation to investigate the power requirements of the aircraft during those flight phases. In the simulation an electric hybrid system consisting of $1.2 \mathrm{KW}$ proton exchange membrane fuel cell (PEMFC) and two $12 \mathrm{~V}$ batteries to power the PiperCub J3 aircraft was implemented. The engine demand load profile was implemented in the programmable electronic load. The aircraft climbs to a height of $10 \mathrm{~m}$ and performs a circuit with a radius of $30 \mathrm{~m}$ before returning to land. Table 1 illustrates the maximum power demands for each stage of the flight. A minimum power demand is considered when the engine is idling with $0 \%$ throttle for the first 15 seconds, while maximum power demands occurred during the take-off and climb stages with $100 \%$ throttle command. These two stages appeared at $\mathrm{t}=15$ seconds and $\mathrm{t}=158$ seconds respectively. For the other three stages, cruising at $\mathrm{t}=107$ seconds, descent at $\mathrm{t}=132$ seconds and landing at $\mathrm{t}=225$ seconds the aircraft required $951 \mathrm{~W}, 402 \mathrm{~W}$ and $172 \mathrm{~W}$, respectively.

Table 1: Power demands of flight phases for the case study.

\begin{tabular}{|c|c|c|c|}
\hline Throttle command (\%) & Phases of flight & Require power (W) & Simulation time (s) \\
\hline $0 \%$ & Idle & 17 & $0-15$ \\
\hline $100 \%$ & Take off & 1285 & $15-107$ \\
\hline $69 \%$ & Cruising & 951 & $107-132$ \\
\hline $50.6 \%$ & Descent & 402 & $132-158$ \\
\hline $100 \%$ & Climb & 1285 & $158-225$ \\
\hline $39 \%$ & Landing & 172 & $225-300$ \\
\hline
\end{tabular}




\section{Results and discussion}

The case study focuses upon using the Nexa hybrid system to meet the electrical engine power demands of the PiperCub J3 aircraft model without a controller. In this hybrid system, the DC/DC converter is connected such that it maintains the output voltage from the FC at $27 \mathrm{~V}$. The rechargeable batteries at the converter output guarantee a stable and dynamic operation of the hybrid system, see fig. 1 . The power requirement for the engine is a function of throttle commands for the various flight phases. Fig. 5 is a plot of throttle commands while figs 6 and 7 show the corresponding power and current demands from the engine. For the first 15 seconds, the engine is at idle and requires $17 \mathrm{~W}$ as shown in fig. 6 , which is entirely provided from the FC. In this period the additional power from the FC is used to charge the battery as shown in fig. 10, where negative battery current in the figure corresponds to the battery being charged.

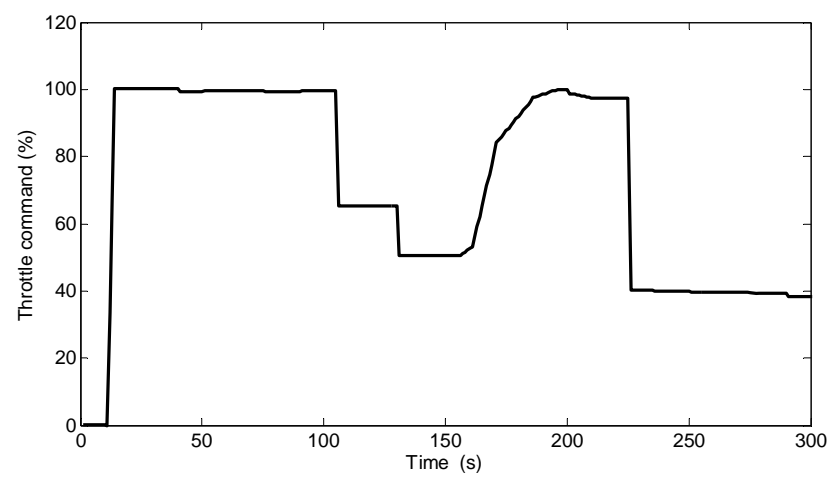

Figure 5: Throttle commands during different flight phases.

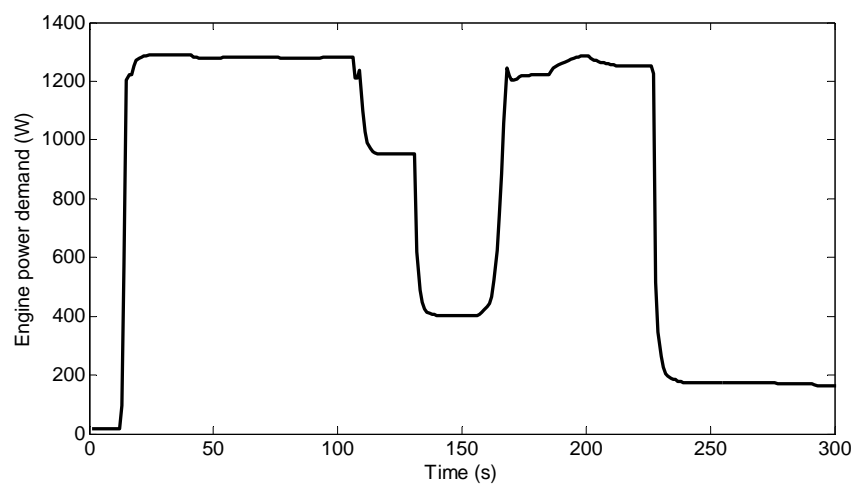

Figure 6: Engine power demand during different flight phases. 


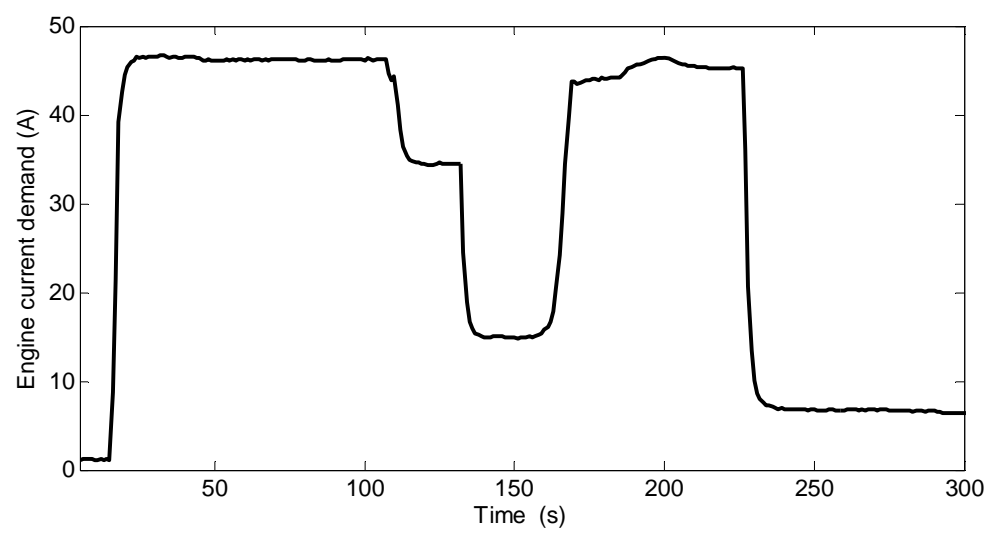

Figure 7: Engine current demand during different flight phases.

During take-off the throttle jumps from $0 \%$ to the maximum value of $100 \%$ in about 3 seconds with the power demand reaching 1285W as shown in figs 5 and 6 . The FC cannot supply all the power demanded during take-off and the FC output voltage decreases from $40.69 \mathrm{~V}$ to $27.27 \mathrm{~V}$, while its stack current increases rapidly from 2.22A to 34.26A at the beginning of the transient interval. Then the voltage continues to fluctuate while the current gradually increases until it reaches $46 \mathrm{~A}$ at 93 seconds, as illustrated in fig. 9. This is explained by the fact that the maximum power demand during the take-off stage is higher than the FC power transient and the extra power must be provided by the batteries. The battery current sharply increases from -1.674A to about 10A in line with throttle demands, see fig. 10. At the end of take-off the battery current tapers down to zero at 107 seconds and the FC current takes over, because the voltage from the FC side is now higher than the voltage from the battery side.

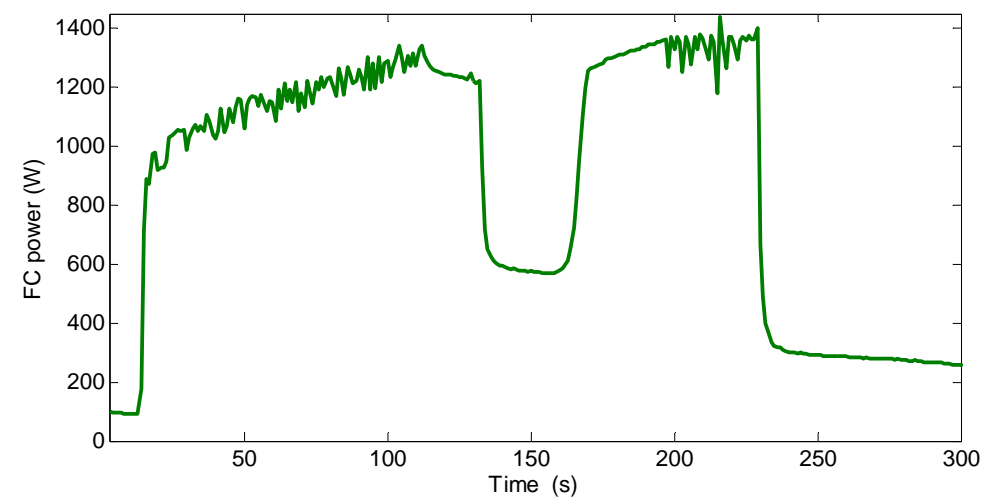

Figure 8: Power produced by the fuel cell during different flight phases. 


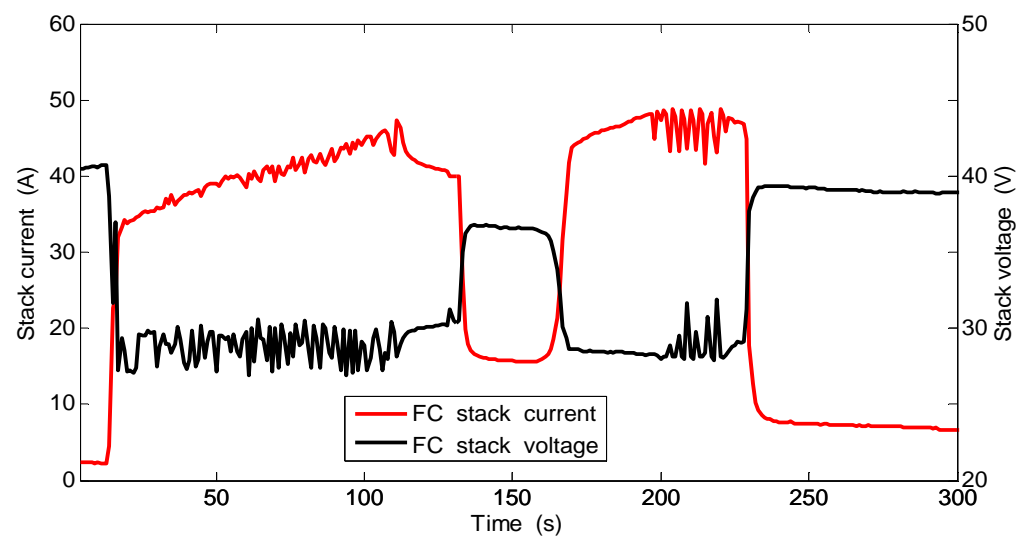

Figure 9: Fuel cell stack voltage and current during different flight phases.

At 107 seconds the aircraft has completed take off and cruises for 25 seconds followed by descend for 26 seconds, during which the power demand drops to $402 \mathrm{~W}$. The FC can now provide power to both the engine and for charging the battery in nominal operating conditions. At 158 seconds, the aircraft now begins a slow climb that requires an engine power of $1285 \mathrm{~W}$ which again demands current from both the FC and battery. However, this time the FC provides almost all the power, the stack current increases rapidly from $16.58 \mathrm{~A}$ to $43 \mathrm{~A}$ and stack voltage simultaneously drops from $36 \mathrm{~V}$ to $28.65 \mathrm{~V}$. The FC current continues to increase gradually to $\sim 48 \mathrm{~A}(1.36 \mathrm{~kW})$ and the stack voltage remains more or less constant at $28.65 \mathrm{~V}$. The FC no longer charges the battery and the battery current changes from $-2.76 \mathrm{~A}$ to $0.72 \mathrm{~A}$. Note very little power is taken from the batteries.

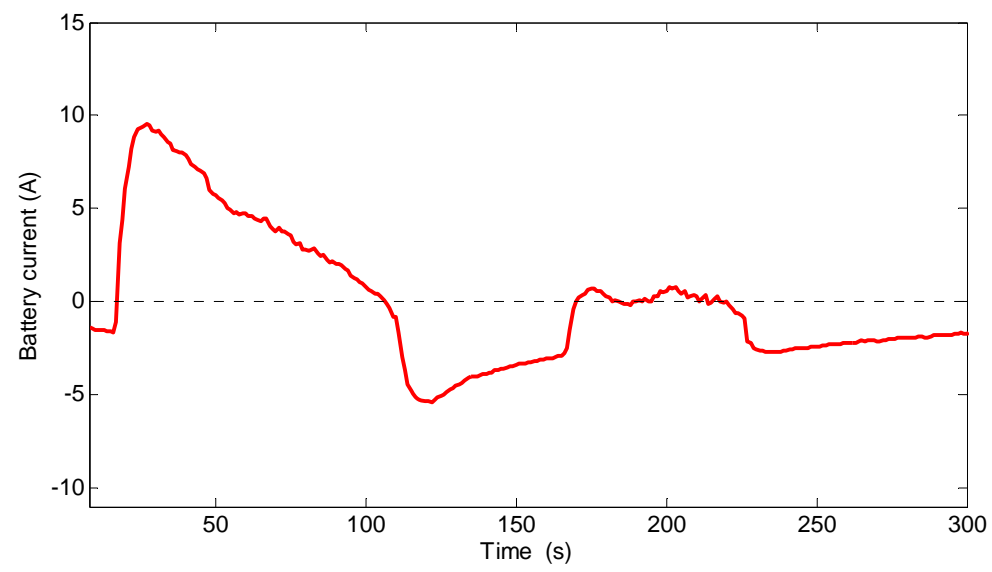

Figure 10: Battery current during different flight phases. 
The slow climb ends at 225 seconds and the aircraft comes in to land. In this last phase of flight the power required is $172 \mathrm{~W}$ and this is supplied entirely by the FC which provides a current $6 \mathrm{~A}$ to the engine and about $2 \mathrm{~A}$ to recharge the batteries. During the flight the batteries supply power only during periods of high transient power demand. Here the power is delivered to the electrical motor from both FC and battery or from only one of them depending entirely on the transient response of power demands without considering the power management between the two sources. The maximum Nexa FC efficiency is about $50 \%$ at part load and drop to $38 \%$ at full power $(1.2 \mathrm{kw})$. It can be seen that the FC is working at very low efficiencies when maximum power demands occur during take-off and climb. Fig. 11 shows the Nexa PEMFC (1.2kW) had consumed 48.5 litres of hydrogen at the end of this flight scenario.

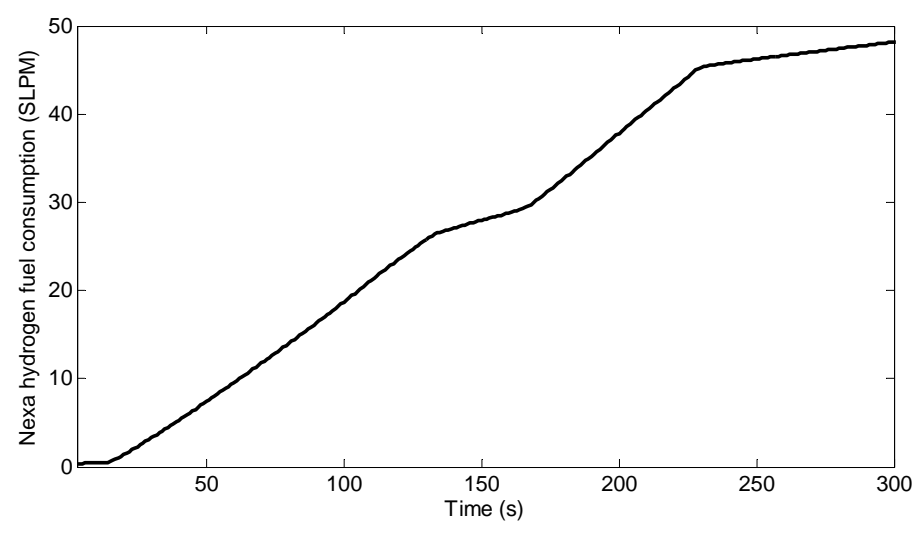

Figure 11: Nexa fuel consumption during different flight phases.

\section{Conclusion}

In this study, the hybrid system consisted of a 1.2kW PEMFC, an unidirectional step-down DC converter and two 12V batteries driving an electrical engine. The converter was connected such that it maintains the output voltage from the FC at $27 \mathrm{~V}$. The rechargeable batteries at the converter output guarantee a stable and dynamic operation of the hybrid system. During the experiment, the engine load profile was implemented via a programmable electronic load. The hybrid system satisfied desired power requirements for different flight phases without controller to manage the power flow between the two sources. The FC was worked at very low efficiency (38\%) while maximum power demands occurred during take-off and climb. During the flight the batteries supply power only during periods of high transient power demand. The Nexa FC consumed 48.5 litres of hydrogen at the end of the flight scenario to satisfy power requirements for different flight phases. 


\section{References}

[1] Nieves Lapeña-Rey, Jonay Mosquera, Elena Bataller, and Fortunato Ortí. First fuel-cell manned aircraft. Journal of Aircraft 2010: 47: 6.

[2] Navarro X. Airbus successfully tests fuel cells in civilian aircraft. Autobloggreen [online journal], Feb $20^{\text {th }} 2008$ [retrieved March 2008].

[3] Lapeña-Rey N, Mosquera J, Bataller E, Ortí F, Dudfield C, Orsillo A. Environmentally friendly power sources for aerospace applications. J Power Sources 2008 7/1: 181(2): 353-62.

[4] Romeo G, Borello F. Design and realisation of two-seater aircraft powered by fuel cell electric propulsion. J The Aeronautical 2010: 114: 1155: 281-297.

[5] http://www.energyor.com/news/post:27; Eo UAV achieves 10 hour flight endurance, 2011, EnergyOR Technologies Inc. 1(514): 744: 6122 [retrieved Feb 2014].

[6] Romeo. G, Borello. F, Cestino. E, Moraglio. I. and Novarese. C. ENFICAFC: Environmental friendly inter-city aircraft and 2-seat aircraft powered by fuel cells electric propulsion. 2005, AIRTEC 2nd International Conference.

[7] James L and Andrew D. Fuel cell systems explained. Second Edition. The Atrium, Southern Gate, Chichester, West Sussex PO19 8SQ, England: John Wiley \& Sons Ltd; 2003.

[8] Jiang Z, Gao L, Blackwelder MJ, Dougal RA. Design and experimental tests of control strategies for active hybrid fuel cell/battery power sources. Journal of Power Sources 2004; 130(1-2): 163-71.

[9] Gao L, Jiang Z, Dougal RA. An actively controlled fuel cell/battery hybrid to meet pulsed power demands. Journal of Power Sources 2004; 130(1-2): 202-7.

[10] Nexa ${ }^{\mathrm{TM}}$ (310-0027) power module user's manual. 2003, Ballard Power Systems Inc.

[11] Sripakagorn A, Limwuthigraijirat N. Experimental assessment of fuel cell/supercapacitor hybrid system for scooters. Int J Hydrogen Energy 2009 8; 34(15): 6036-44.

[12] www.isle-ilmenau.de/gmbh/produkte/bsz/datasheet_PG_1200.pdf; D.C.-D.C. converter BSZ PG 1200 [retrieved March 2014].

[13] http://sine.ni.com/nips/cds/view/p/lang/en/nid/1180;

Shielded I/O connector block for DAQ devices with 68-pin connectors, National instruments [retrieved March 2014].

[14] http://www.amploc.com/; Amploc world center of the current sensing, [retrieved June 2011]. 